\title{
Is routine blood test of value for evaluating health effects among midwives working with nitrous oxide for pain relief in delivery unit
}

\author{
Gudrun Abascall ${ }^{1}$, Maud Johansson ${ }^{1}$, Jan Jakobsson ${ }^{2}$ \\ ${ }^{1}$ BB Stockholm, Stockholm, Sweden; \\ ${ }^{2}$ Department of Anaesthesia \& Intensive Care Institution for Physiology and Pharmacology, Karolinska Institutet, Stockholm, SWE- \\ DEN; *Corresponding Author: Jan.jakobsson@ki.se;
}

Received 2 January 2011; revised 20 January 2011; accepted 25 February 2011.

\begin{abstract}
Chronic workplace exposure to high nitrous oxide concentrations has been suggested to potentially be associated to negative health effects caused by the interference with the vitamin B12, methionine synthase pathway. The objective of the present study was to determine if delivery unit work place ambient air nitrous oxide exposure results in detectable hyperhomocysteinemia or signs of macrocytocis in personnel. Blood samples from thirty healthy female fulltime employees, midwives, aged 43 (range 25-62) years were studied. Routine blood test analysed for plasma homocysteine and blood status; haemoglobin, mean corpuscular volume, mean corpuscular haemoglobin concentration, blood status was analysed once before going on vacation and repeated after at least 10 days' leave, nitrous oxide free period. Median time weighted average was 41 [10 - 547] ppm; 3 out of 11 TWA measurements were above recommended100 ppm limit. Median homocysteine concentrations were 10.7 [5.6 - 16] micromol/L with reference limits of $5.0-15 \mathrm{micromol} / \mathrm{L}$. Megaloblastic erythrocytes was not detected in any personnel and no changes in blood status could be detected between before and after a nitrous oxide-free period. Conclusions: One of 3 delivery units' ambient air quality measures exceed recommended ranges. No signs of routine blood test pathology could be seen in the personnel studied.
\end{abstract}

Keywords: Nitrous oxide; ambient air quality; TWA; homocysteine; megaloblastic anaemia.

\section{INTRODUCTION}

Chronic working day exposure to nitrous oxide in healthcare workers is associated with alterations of vitamin B12 metabolic status, the extent of which depends on the level of exposure [1]. Air conditioning and an efficient pressure/exhaust ventilation (above 12 air exchanges/h) together with efficient active scavenging systems are sufficient to sustain $\mathrm{N}(2) \mathrm{O}$ exposure in operating theatres at levels below or within the OEL value of $180 \mathrm{mg} / \mathrm{m}(3)$ [2]. Ventilation and scavenging is not always optimal in maternity wards and work place exposure has been shown to be not uncommonly exceeding set national recommendation, occupational exposure limits $[3,4]$. The use of scavenging equipment is not always easily adopted in the delivery situation with mothers experiencing painful contractions [5].

The inhibitory effects of nitrous oxide on the vitamin B12 dependent methionine synthase pathway have been suggested to be one of major factors for the developments of negative health effects [6]. Homocysteine and megaloblastic erythrocytes and anaemia are early signs from prolonged nitrous oxide exposure triggered methionine synthase inhibition $[7,8]$.

The aim of this study was to explore if any changes could be seen in routine blood testing as signs of nitrous oxide inhibition on the methionine synthase pathway in full-time delivery room personnel.

\section{METHODS}

The study was conducted in delivery unit of Stockholm BB. Annual numbers of deliveries is about 2800 in the unit. Nitrous oxide is the most commonly used analgesic technique used, $73 \%$ of mothers uses nitrous oxide as some point during the delivery. Nitrous oxide is administered via an on-demand valve from a dedicated nitrous oxide oxygen mixture Ventyo (Linde Healthcare, AGA $A B$, Lidingö, Sweden). The system use includes a basic waste gas scavenging system but no "double-mask scavenging" is available. Time Weighted Average (TWA) for 
nitrous oxide was measured on eleven random 8-hour workdays using nitrous oxide diffusion samplers (Dräger Safety AG \& Co. KGaA, Lubeck, Germany).

After informed consent, venous blood samples for analysis of plasma homocysteine and blood status were taken in 30 healthy full-time female personnel, aged 43 (range 25-62) years. A second blood status was analysed after vacation a nitrous oxide-free period in all 30 subjects, each subject serving as its own control. All blood samples were immediately frozen. Standard hospital laboratory techniques were use to analyse all samples for plasma homocysteine, haemoglobin value ( $\mathrm{Hb}$ ), hematocrit, erythrocytes, mean corpuscular haemoglobin (MCH), mean corpuscular volume (MCV), mean corpuscular haemoglobin concentration (MCHC) and leucocytes.

Statistics: All data are given as mean and standard deviation or median and range.

\section{RESULTS}

Work place nitrous oxide concentration TWA varied considerably with a median of eleven measured TWA of 41 [10 - 547] ppm. Three of the 11 TWA measurements were above the recommended Swedish maximum TWA of $100 \mathrm{ppm}$. Median homocysteine concentrations were 10.7 [5.6 - 16] micromol/L with reference limits of 5.0 $15 \mathrm{micromol} / \mathrm{L}$. Concentrations of $16 \mathrm{micromol} / \mathrm{L}$, just above the upper reference limit, were found in 2 midwives. The plasma levels of homocysteine for these two nurses did not change after a vacation period of at least 14 days free from exposure to nitrous oxide. Haematological test results are shown in Table 1. Four personnel had mild anaemia that showed a tendency to improve following a vacation period; haemoglobin before/after vacation; 116/120, 103/108, 111/118, 118/123 respectively. No signs of megaloblastic erythrocytes of megaloblastic anaemia were seen in any of these or any other of the midwives. All MCH, MCV or MCHC values were within reference ranges and there were no systematic changes in any variable when compared before versus after vacation Table 1. The mean duration of vacation was 23 [10-44] days. Mean change in MCHC before versus after vacation was $-0.4[-17$ to +15$]$. Individual changes in MCHC concentrations are shown in Figure 1.

\section{DISCUSSION}

Our results are mixed, the ambient air quality measures showed that further efforts have to be taken in order to apply to national recommendations. We could, however, no see any clear signs of blood pathology attributable to a potential more profound inhibition of the methionine synthase pathway. Most countries provide clear guidelines as to work place ambient air concentrations for
Table 1. Blood status in 30 midwifes before and after vacation (mean and range).

\begin{tabular}{|c|c|c|}
\hline & Before vacation & After vacation \\
\hline Haemoglobin (g/L) & 129.1 [103-154] & 130.9 [108-146] \\
\hline Erythrocyte volume fraction & 37.9 [32-45] & 38.5 [34-43] \\
\hline $\begin{array}{l}\text { Mean corpuscular volume } \\
\left(\times 10^{-15} \mathrm{~L}\right)\end{array}$ & 87.4 [74-96] & 88.2 [74-98] \\
\hline $\begin{array}{l}\text { Mean corpuscular } \\
\text { haemoglobin }\left(10^{-9} \mathrm{~g}\right)\end{array}$ & 29.7 [24-33] & 29.9 [24-33] \\
\hline $\begin{array}{l}\text { Mean corpuscular } \\
\text { haemoglobin } \\
\text { concentration }(\mathrm{g} / \mathrm{L})\end{array}$ & 340.2 [325-352] & 339.1 [320-352] \\
\hline Platelets $\left(\times 10^{9} / \mathrm{L}\right)$ & 246 [171-418] & 254 [168-398] \\
\hline Leucocytes $\left(\times 10^{9} / \mathrm{L}\right)$ & $6.0[4.4-9.5]$ & $6.3[4.4-9.6]$ \\
\hline
\end{tabular}

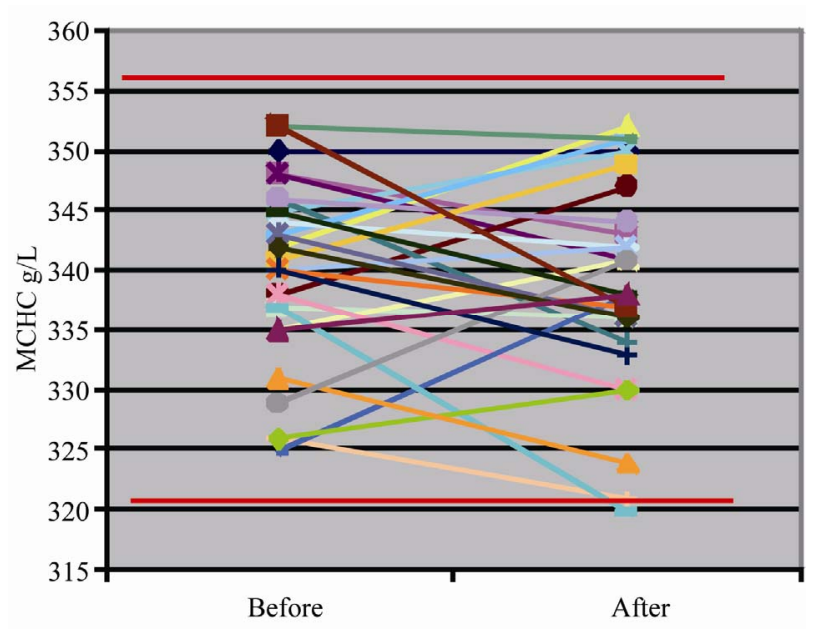

Figure 1. Individual mean corpuscular haemoglobin concentrations (g/L) for 30 personnel exposed to nitrous oxide, before and after vacation. Bold lines show normal limits.

gases possessing potential health risk. In the US as well as in most European nations nitrous oxide have wellestablished time- weighted average limits that should not be exceeded in order to assure personnel safety and health [9]. These limits are in parts per million range varying in the magnitude of 25 - 100 parts per million (ppm). Gas concentrations in parts per million are difficult to measure and today there is no easily available technique to on every day basis monitor and secure good work place air quality. We found that ambient nitrous oxide concentration varied considerably and almost a third of measured TWA values were above national recommended limits for Sweden.

Operating room with forced basic ventilation in combination with commonly adopted routines in order to minimise work-place pollutions by means of avoidance of mask ventilation use of laryngeal mask airway and 
intubation and low-fresh gas flows have made incidence of personnel exposure to nitrous oxide above set recommendation infrequent (10). The large variation in nitrous oxide work place exposure detected in our unit is similar with what has been found elsewhere. Recent report both from UK and Sweden have shown high incidences of TWA above set national recommendations in delivery units $[3,4]$. It is obvious that further efforts to improve ambient workplace air quality are warranted in the delivery unit studied. The importance of adequate ventilation and scavenging is well acknowledged [4]. In our centre the nitrous oxide is administered from an on-demand valve attached to a standard a scavenging system. The problem with adequate scavenging of exhaled air associated with the use of nitrous oxide during childbirth, in association to painful contractions is wellknown [5].

Homocysteine increase has been suggested to be a sensitive marker for the inhibitory effect of nitrous oxide on this enzyme complex [11]. We found, however, no signs of nitrous oxide associated hyperhomocysteinaemia. In the two midwifes exhibiting borderline values during a period of consistent work, no change could be noticed after a period of 10 days without any nitrous oxide exposure. Furthermore neither of these two personnel showed any signs of blood status abnormalities. Megaloblastocis and megaloblastic anaemia are signs of vitamin B12 deficiency and such changes have been shown in patient following nitrous oxide anaesthesia [12, 13]. No signs of megaloblastocis and no changes in mean corpuscular volume or mean corpuscular haemoglobin concentrations were found in any of the subjects studied. All individual values were within normal ranges and no signs of change in any erythrocyte variable could be found when each subject acted as its own control and values following a longer period of work were compared with values after at least 10 days of vacation.

Personnel health is an important topic and all efforts should be taken to secure good work environment. It is hard to help personnel to check their workplace compliance to set guidelines as the recommended trace concentrations limits are extremely low. Furthermore, the absolute safe exposure limits is not known. Blood status and homocysteine analyses are easy to perform and have well verified normal ranges. The literature on screening of health aspects in personnel working in risk environments is sparse. Salo et al studied peripheral blood in operating room personnel and found similar to us no signs of B12-nitrous oxide interaction [14].

This is an entirely explorative pilot study. No interventions were made, we studied every day clinical practice and had blood samples from personnel without control of concomitant diseases, nutritional status etc. We had the intention to see if any signs or signals of adverse effects of work place nitrous oxide exposure could be detected from routine blood tests having the midwifes as their own control, before and after at least a week without any nitrous oxide exposure.

In conclusion, high ambient nitrous oxide concentrations above set national occupational exposure limits were seen in about $1 / 3$ of measures and further efforts in order to reduce personnel exposure has been initiated. We could see no signs of hyperhomocysteine or blood status pathological influences of nitrous oxide. Further studies are warranted to determine whether routine blood test could be of value to discriminate potential health effects.

Conflicts of interest statement: Jan Jakobsson is consultant doing safety review for Linde Healthcare, Gudrun Abascall is Chief-midwife for the unit, and no other of the authors has any actual or potential personal or financial conflicts of interest.

\section{REFERENCES}

[1] Krajewski, W., Kucharska, M., Pilacik, B., Fobker, M., Stetkiewicz, J., Nofer, J.R. and Wronska-Nofer, T. (2007) Impaired vitamin B12 metabolic status in healthcare workers occupationally exposed to nitrous oxide. British Journal of Anaesthesia, 99, 812-818.

doi:10.1093/bja/aem280

[2] Krajewski, W., Kucharska, M., Wesolowski, W., Stetkiewicz, J. and Wronska-Nofer, T. (2007) Occupational exposure to nitrous oxide - the role of scavenging and ventilation systems in reducing the exposure level in operating rooms. International Journal of Hygiene and Environmental Health, 210, 133-138. doi:10.1016/j.ijheh.2006.07.004

[3] Henderson, K.A., Matthews, I.P., Adisesh, A. and Hutchings, A.D. (2003) Occupational exposure of midwives to nitrous oxide on delivery suites. Occupational and Environmental Medicine, 60, 958-961. doi:10.1136/oem.60.12.958

[4] Westberg, H., Egelrud, L., Ohlson, C.G., Hygerth, M. and Lundholm, C. (2008) Exposure to nitrous oxide in delivery suites at six Swedish hospitals. International Archives of Occupational and Environmental Health, 81, 829-836. doi:10.1007/s00420-007-0271-3

[5] Chessor, E., Verhoeven, M., Hon, C.Y. and Teschke, K. (2005) Evaluation of a modified scavenging system to reduce occupational exposure to nitrous oxide in labor and delivery rooms. Journal of Occupational and Environmental Hygiene, 2, 314-322. doi:10.1080/15459620590959722

[6] Chanarin, I. (1980) Cobalamins and nitrous oxide: A review. Journal of Clinical Patholology, 33, 909-916. doi:10.1136/jcp.33.10.909

[7] Louis-Ferdinand, R. T. (1994) Myelotoxic, neurotoxic and reproductive adverse effects of nitrous oxide. Adverse Drug Reaction Toxicology Review, 13, 193-206.

[8] Szymanska, J. (2001) Environmental health risk of chronic exposure to nitrous oxide in dental practice. Annals of 
Agricultural \& Environmental Medicine, 8, 119-122.

[9] Byhahn, C., Wilke, H.J. and Westpphal, K. (2001) Occupational exposure to volatile anaesthetics: Epidemiology and approaches to reducing the problem. CNS Drugs, 15 , 197-215. doi:10.2165/00023210-200115030-00004

[10] Anderson, R.E., Barr, G, and Jakobsson, J.G. (2005) Operating room nitrous oxide trace concentrations: A clinical study in ambulatory surgery. Ambulatory Surgery, 12, 23-26. doi:10.1016/j.ambsur.2004.10.002

[11] Ermens, A.A., Refsum, H., Rupreht, J., Spijkers, L.J., Guttormsen, A.B. and Lindemans, J. (1991) Monitoring cobalamin inactivation during nitrous oxide anesthesia by determination of homocysteine and folate in plasma and urine. Clinical Pharmacolology Therapeutics, 49, 385-393. doi:10.1038/clpt.1991.45
[12] Stabler S.P, Allen R.H, Savage D.G, Lindenbaum J. (1990) Clinical spectrum and diagnosis of cobalamin deficiency. Blood, 76, 871-881.

[13] Deleu, D., Louon, A., Sivagnanam, S., Sundaram, K., Okereke, P. and Gravell. (2000) Long-term effects of nitrous oxide anaesthesia on laboratory and clinical parameters in elderly Omani patients: A randomized double-blind study. Journal of Clinical Pharmacy and Therapeutics, 25, 271-277. doi:10.1046/j.1365-2710.2000.00287.x

[14] Salo, M., Rajamäki, A. and Nikoskelainen, J. (1984) Absence of signs of vitamin B12--nitrous oxide interaction in operating the theatre personnel. Acta Anaesthesiologica Scandinavica, 28, 106-108. doi:10.1111/j.1399-6576.1984.tb02021.x 